Proceedings of the Operational Research Society Simulation Workshop 2021 (SW21)

M. Fakhimi, D. Robertson, and T. Boness, eds.

DOI: https://doi.org/10.36819/SW21.044

\title{
ASSET AND LIABILITY MANAGEMENT IN INSURANCE FIRMS: A BIASED-RANDOMISED APPROACH COMBINING HEURISTICS WITH MONTE-CARLO SIMULATION
}

\author{
Mr. Armando Nieto \\ Divina Pastora Seguros \\ Calle Xativa 23 \\ 46004 Valencia, SPAIN \\ armando.nieto@divinapastora.com
}

\author{
Dr. Angel A. Juan \\ Dr. Christopher Bayliss \\ Universitat Oberta de Catalunya - IN3 \\ Av. Carl Friedrich Gauss 5 \\ 08860 Castelldefels, SPAIN \\ \{ajuanp, cbayliss\}@uoc.edu
}

\author{
Dr. Renatas Kizys \\ University of Southampton \\ University Road \\ Southampton SO17 1BJ, UK \\ r.kizys@soton.ac.uk
}

\begin{abstract}
The management of assets and liabilities is of critical importance for insurance companies and banks. Complex decisions need to be made regarding how to assign assets to liabilities such in a way that the overall benefit is maximised over a multi-period horizon. At the same time, the risk of not being able to cover the liabilities at any given period must be kept under a certain threshold level. This optimisation problem is known in the literature as the asset and liability management (ALM) problem. In this work, we propose a biased-randomised algorithm to solve a real-life instance of the ALM problem. Firstly, we outline a greedy heuristic. Secondly, we transform it into a probabilistic algorithm by employing Monte-Carlo simulation and biased-randomisation techniques. According to our computational tests, the probabilistic algorithm is able to generate, in short computing times, solutions that outperform by far the ones currently practised in the sector.
\end{abstract}

Keywords: Heuristics, Asset and Liability Management, Biased Randomised Algorithm, Monte Carlo

\section{INTRODUCTION}

Financial institutions have to face some critical risk-management processes (Cornett and Saunders 2003). Among such processes, asset and liability management (ALM) is of paramount importance due to its potential consequences. ALM consists of a range of techniques necessary to invest adequately, so that the firm's long-term liabilities are met (Ziemba et al. 1998). For an insurance company, a liability constitutes the legal responsibility to repay the insurance contributions that the customer has been making over an agreed length of time, which are increased by the interest rate. This is a typical transaction of pension or life insurance intended to secure retirement income, which gives rise to a three-tier financial problem. First, the insurance company receives the customer's premium. Second, the company invests this premium in the long term, so that the financial benefit envisaged in the insurance policy is secured. Third, in the event of the customer's retirement or death, the insurance company needs to have sufficient funds to meet 
its liability to the customer. While the aforementioned financial problem unfolds, the insurance company is confronted with a range of risks, which arise either from its role as a financial intermediary or due to adverse regulatory as well economic and social policies. If the insurer's obligation to the customer is not honoured, its default becomes a likely scenario. A default can be very costly for the firm, since it can inflict a loss of credibility and reputation. On the one hand, it can face a legal action from its creditors. As a result the insurer may be forced to pay hefty fines by the regulatory body. On the other hand, the firm's market share may diminish as its customers may switch to other insurers.

It is thus not surprising that the ALM problem has been widely studied in the literature. As interest rates vary over time, the present value of both assets and liabilities responds to such variation. Consequently, optimal and smart asset management solutions become critical to the insurer, who seeks to ensure that the liabilities can be met at the time when they are required, while at the same time, the value of the firm is maximised. In practical applications, one of most popular solutions to this asset management problem is the so-called cash-flow matching (Iyengar and Ma 2009), whose main objective is to ensure the timely payment of the liabilities. In some European countries, the legislation does not envisage any specific mechanism to ensure that the firm's obligations are met. Instead, capital is regulated by targeting the value of the reserves that the company needs to build on its balance sheet. In general, regulations impose a specific interest rate to calculate the provisions of the firm's liabilities over the short and medium term. Sufficient provisions are required to achieve the solvency of the firm. Furthermore, if the firm's manager can prove that its assets are adequate to cover its liabilities in the long term, the firm is granted permission to use a higher interest rate in its provisions. This allows its capital value on the balance sheet to be lower.

Heuristic and metaheuristic algorithms have become a new standard when dealing with complex and large-scale portfolio optimisation and risk management problems (Doering et al. 2019). Hence, in this paper we propose a heuristic-based algorithm to find out which assets of a firm's portfolio can be efficiently used to reduce the risk of default liability while minimising the monetary cost for the company. Our approach combines Monte Carlo simulation (MCS) with a greedy heuristic. This combination results in a biased-randomised probabilistic algorithm. Biased-randomised algorithms make use of random sampling from a skewed probability distribution (e.g., a geometric one) in order to 'inject' some non-uniform (oriented) randomness into a greedy heuristic. That way, the latter is transformed into a more efficient probabilistic algorithm without losing the logic behind the heuristic (Grasas et al. 2017). The rest of the paper is structured as follows. Section 2 provides a brief literature review on ALM, while Section 3 reviews biased-randomised algorithms using MCS. Section 4 discusses the typical cash-flow behaviour in both assets and liabilities. Section 5 outlines the optimisation problem. Then, Section 6 proposes a greedy heuristic as an initial solving method, while Section 7 extends the aforementioned heuristic into a probabilistic algorithm. A series of computational experiments, based on real-life data, are carried out in Section 8. Finally, Section 9 concludes.

\section{RECENT WORK ON ASSET AND LIABILITY MANAGEMENT}

The scientific literature on ALM is quite extensive and covers several decades. Due to space limitations, we focus on research published over the last two decades. Stochastic programming models have been widely used to improve financial operations and risk management. Hence, building on multi-stage stochastic programming to model a pension fund, Kouwenberg (2001) develop scenario-generation methods for the ALM. Gondzio and Kouwenberg (2001) combine decomposition methods and high-performance computing to cope with large-scale instances of the problem. They simulate over 4 million scenarios, 12 million constraints, and 24 million variables to study a pension fund. Dempster et al. (2003) combines dynamic stochastic optimisation with Monte Carlo simulation to analyse an ALM problem involving global asset classes and contribution pension plans. Arguably, their approach can also be used to manage financial planning problems related to insurance firms, risk capital allocation, and corporate investment, among others. Additional applications and case studies on ALM can be found in Zenios and Ziemba (2007). Also, Kouwenberg and Zenios (2008) review stochastic programming models for ALM. Among other issues, they 
analyse the performance of these models when applied to pension funds, discussing both their advantages and limitations.

More recently, Ferstl and Weissensteiner (2011) consider a multi-stage ALM under time-varying investment opportunities. To minimise the conditional value at risk of shareholder value, the authors utilise stochastic linear programming and a decomposition of the benefits in dynamic re-allocation. Examples of specialised books dedicated to ALM are Bauer et al. (2006), Adam (2008), Mitra and Schwaiger (2011), and Choudhry (2011). Gülpinar and Pachamanova (2013) present an ALM model based on robust optimisation techniques. Their model incorporates a time-varying aspect of investment opportunities. These authors perform a series of computational studies with real market data in order to compare the performance of their approach to that of classical stochastic programming. More recent approaches to ALM focus on the mean-variance ALM with constant elasticity of variance (Zhang and Chen 2016), random coefficients (Wei and Wang 2017), or stochastic volatility (Li et al. 2018). Fernández et al. (2018) introduce a stochastic ALM model for a life insurance company. They use GPUs to run Monte Carlo simulations in parallel. Dutta et al. (2019) employ big data analytics and stochastic linear programming in ALM under uncertainty scenarios. The authors study the relevance of employing a large number of scenarios in solving the stochastic ALM problem. Finally, Li et al. (2019) use a multi-period mean-variance model to analyse an ALM problem with probability constraints. In their model, investors seek to control for the probability of bankruptcy, while the process is influenced by uncertainty in the cash flows.

\section{RECENT WORK ON BIASED-RANDOMISED ALGORITHMS}

Different examples on the use of Monte Carlo simulation methods to guide the search of heuristic-based algorithms can be found in the literature (Faulin and Juan 2008, Faulin et al. 2008, Juan et al. 2009). One particular case is that of biased-randomisation (BR) techniques. As described in detail by Grasas et al. (2017), BR techniques make use of Monte-Carlo simulation and skewed probability distributions in order to transform a greedy heuristic into a probabilistic algorithm without losing the logic behind the heuristic. This transformation is achieved after sorting each constructive movement by a given criterion and then assigning diminishing probabilities of being selected as the movement becomes less promising. In practice, the use of randomised greediness here allows for a fuller exploration of the solution space, but with the advantage that the effective logic behind the greedy heuristic is retained (Figure 1).

BR techniques have been successfully used during the last years to solve different rich and realistic variants of vehicle routing problems (Dominguez et al. 2016, Calvet et al. 2016), permutation flow-shop problems (Martin et al. 2016, Gonzalez-Neira et al. 2017), location routing problems (Quintero-Araujo et al. 2017), facility location problems (De Armas et al. 2017), waste collection problems (Gruler et al. 2017), horizontal cooperation problems (Quintero-Araujo et al. 2019), and constrained portfolio optimisation problems (Kizys et al. 2019).

\section{CASH FLOWS OF LIABILITIES AND ASSETS}

Under an insurance policy, the insurer is liable to pay whenever the event described in the contract takes place. This is a 'must' obligation that the insurer has to honour. Otherwise, the company would face a hefty monetary fine, its reputation would be severely damaged, and its administrators could be taken to court. The insurer's liabilities comprise all policies subscribed by its customers. This aggregation results in an irregular and difficult-to-predict cash flow structure. Indeed, each policy has a different maturity and size, and is bound to a set of conditions. Being based on real-life data, Figure 2 shows a typical example of how liabilities are distributed over a period of 30 years. Figure 2 unveils a long term liability schedule, which sheds light on frequent cash flows arising from transactions in each time period. To complicate things further, these liabilities are not static, since a common policy can end in different ways: $(i)$ when a customer decides to cancel it; (ii) when the policy reaches its maturity date; or (iii) when the customer dies. 


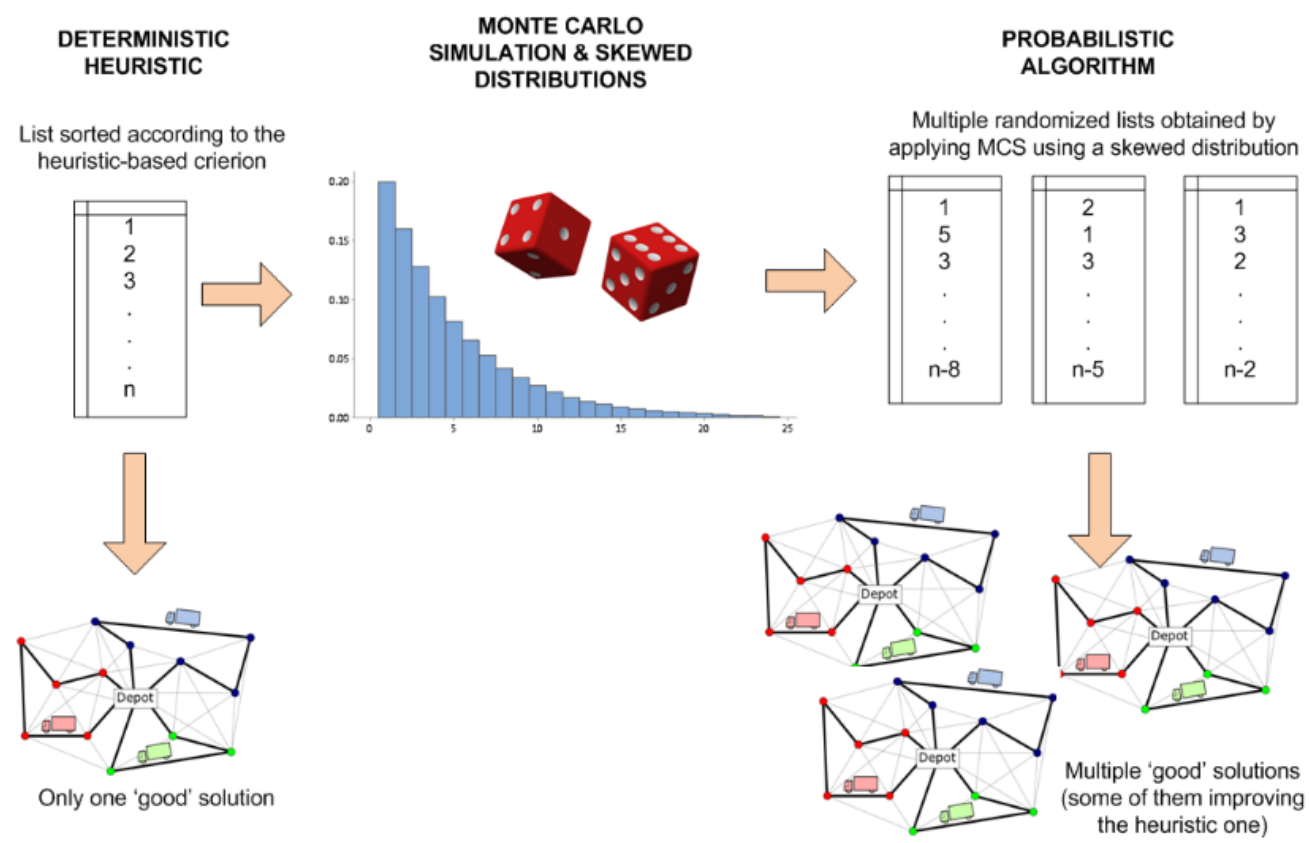

Figure 1: Schematic representation of the biased-randomisation process.

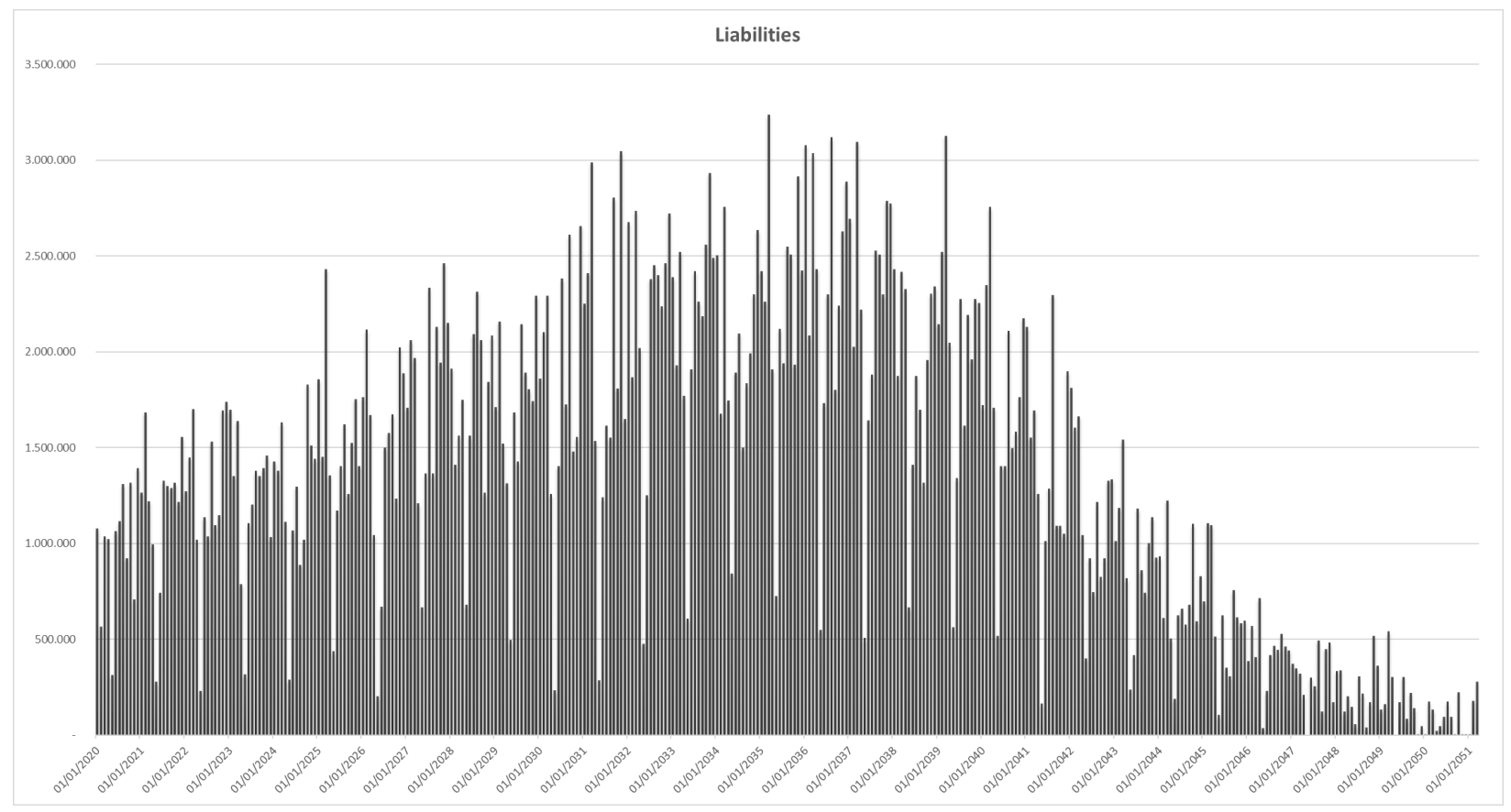

Figure 2: Liability cash-flow profile of a hypothetical portfolio.

On the flipside of the insurer's balance sheet, the manager is tasked to select a set of assets to cover the liabilities in each period. Because of the opportunity cost of these assets, the total value of these selected values should be just the necessary one, since these assets remain 'frozen' and cannot be used for any other purpose. In other words, once the assets that will cover the firm's liabilities have been selected, they 
cannot be used in any other transaction. Therefore, this results in an optimisation problem, in which a set of minimum-value assets has to be determined to cover the firm's liabilities. If liabilities are assumed to be static (deterministic), assets can be optimally selected in advance. Corporate and government bonds are the predominant asset classes in the insurance market, since returns on a bond market investment can be accurately predicted in advance. The static assumption makes it simpler to predict the value of assets, as opposed to the value of liabilities. It is also worth noting that assets feature a significantly shorter span time than liabilities. For instance, while insurance contracts cover the customer's retirement or full life - which can span over 45 years - typical maturities of bond market instruments do not extend beyond 30 years. This generates a maturity mismatch between assets and liabilities. In addition, while liability cash flows might arise at any moment in time, the cash-flow structure of assets is more concentrated around some particular time periods. Figure 3 shows a typical asset portfolio associated with an insurance company. If we compare this structure with the previous one for liabilities, we can observe remarkable differences that suggest a non-trivial matching problem.

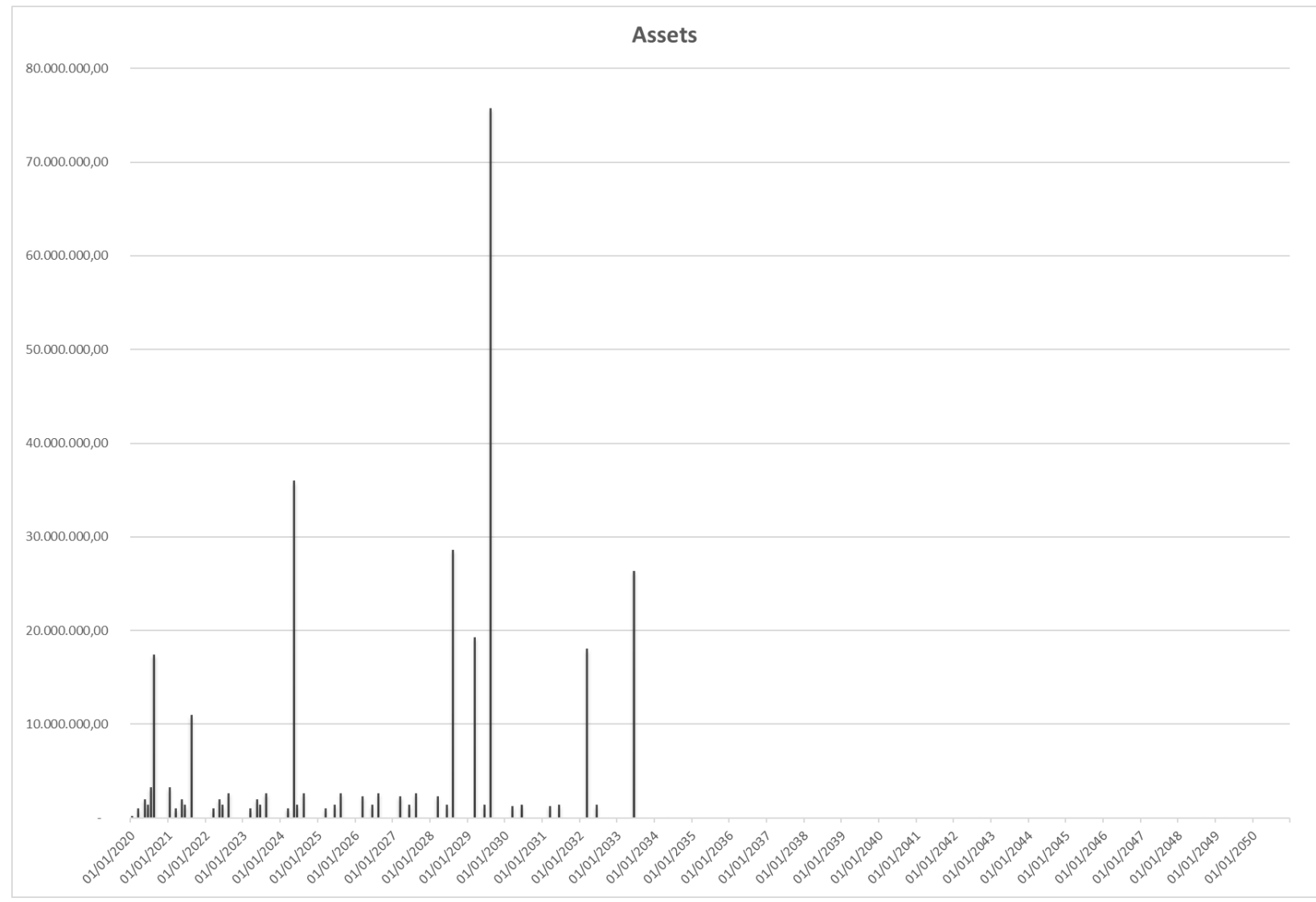

Figure 3: Asset cash-flow profile in a typical portfolio.

\section{THE FINANCIAL BALANCE PROBLEM}

The financial balance problem consists of choosing a portfolio of assets and blocking them just to match the liabilities. Thus, the insurer needs to manage the income arising from assets, invest it in the short term, and use the investment to pay the liabilities claimed by its customers. If its assets do not generate sufficient cash flows, then the insurance company needs to borrow, which inflicts a penalty cost. Accordingly, it is possible to formulate the financial balance as follows, where $t=0,1,2, \ldots, T$ represents the time period: 


$$
S_{0}=A_{0}-L_{0} \quad \text { and } \quad S_{t}=\left\{\begin{array}{cc}
S_{t-1} r_{t-1, i}+A_{t}-L_{t} & \text { if } S_{t-1} \geq 0 \\
S_{t-1}\left(r_{t-1, t}+\delta\right)+A_{t}-L_{t} & \text { if } S_{t-1}<0
\end{array} \quad \forall 1 \leq t \leq T\right.
$$

In Equation (1) $S_{0}\left(S_{t}\right)$ is the capital in period $0(t), A_{0}\left(A_{t}\right)$ denotes the value of assets in period $0(t)$, $L_{0}\left(L_{t}\right)$ denotes the value of liabilities in period $0(t)$, and $r_{t-1, t}$ is the interest rate used to capitalise the resources from period $t$ to $t-1$. Finally, $\delta$ represent the bid-ask spread on the interest rate. it is worth noting that Equation (1) is recursive, and the balance sheet sign determines if the bid or the ask interest rate is used to capitalise the resources until the next term. If the balance is negative, the company will need to borrow. As a result, it will need to pay the ask interest rate on the credit line, which will require more capital. Notably, the selected assets have an effect on the balance sign, creating a binary tree of $2^{T}$ nodes. Moreover, if the balance falls negative its size is restricted by the credit limit.

Based on the aforementioned, we are now in a position to outline an optimisation program that solves for the optimal choice of the assets and the associate weights to match the liabilities. On an individual basis, let $A_{t}^{j}$ be the portfolio of the firm's assets, where super-index $j$ refers to a particular asset, and the sub-index $t$ refers to the cash flow of asset $A^{j}$ in period $t$. Let $L_{t}$ be the cash flow associated with liabilities in period $t$.

The goal is to select a portion $\alpha^{j}$ of each asset $A^{j}$ with the following goal:

$$
\min \sum \alpha^{j} P V\left(A^{j}\right)
$$

where $P V$ is the present value, which is computed using the term structure of interest rates. Moreover, the selection of assets is subject to the following constraints, where $\tau$ refers to the maximum credit line of the firm:

$$
\begin{array}{r}
S_{0}=A_{0}-L_{0} \\
S_{n} \geq 0 \\
\forall t \geq 1 \quad S_{t}>=-\tau
\end{array}
$$

\section{A GREEDY HEURISTIC}

In this section we propose a greedy heuristic that finds a selection of our assets, $\alpha^{j}$. In the next section, this heuristic is extended into a biased-randomised algorithm, which allows to improve the solutions provided by the greedy heuristic. The heuristic constructs a feasible solution, one step at a time, by always choosing the 'best-next-move' in the short run (i.e., without taking into account the possible long-run implications of this selection). For that, we consider that the liability cash flow can be estimated by aggregating individual cash flows in each period of time. Then, we are interested in solving a simplified matching problem, which considers just the cash flow associated with one of these liabilities; the specific liability is randomly selected. Once the chosen liability has been matched by a set of assets, a new liability cash flow is randomly chosen and new assets (from the remaining ones) are drawn to cover it. This process is re-iterated until all the liabilities have been covered by asset cash flows (Algorithm 1).

Notice that the first step in Algorithm 1 is to decide an order for the list of liability cash flows. A natural order is the one given by the maturity date, so that the next-in-time cash flow that will have to be payed is introduced first, the second one is next, and so on. The selection of the best asset is quite simple, since we have to match only one liability cash flow at a time. Hence, we only have to iterate over the remaining assets to get the minimum fraction needed to match our new liability. Only assets with a value larger than the current liability value are considered. 


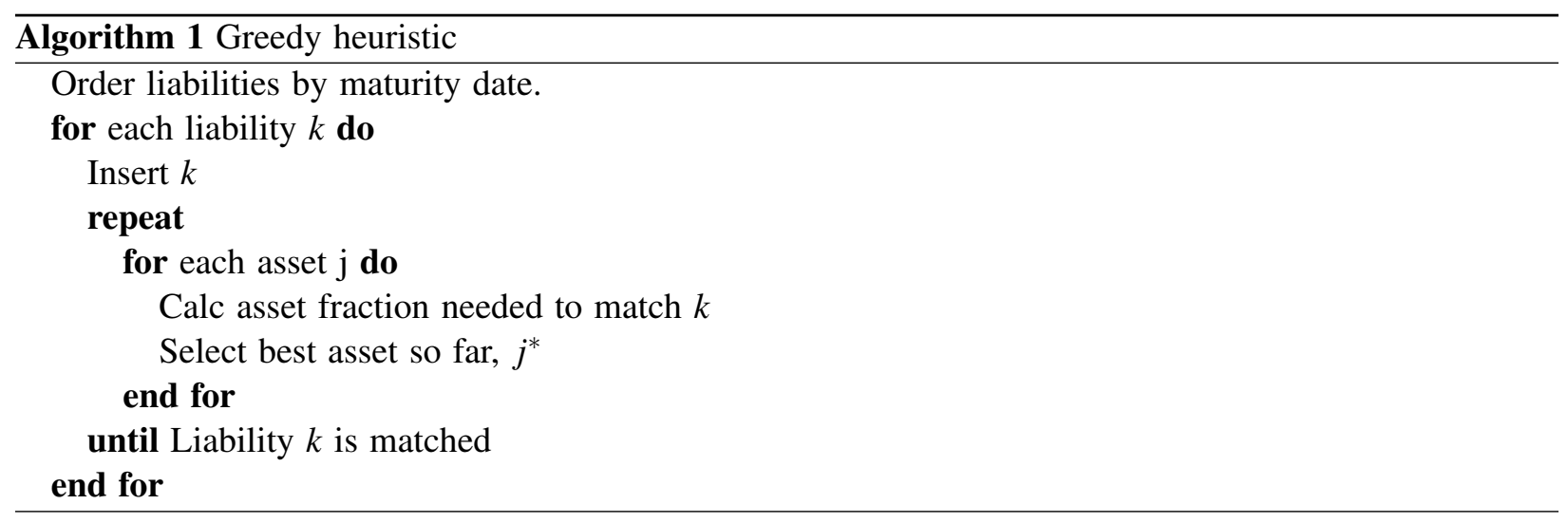

\section{A BIASED-RANDOMISED ALGORITHM}

By examining Algorithm 1, one can notice the following: once the order of the liabilities to be matched has been fixed, the solution (set of assets chosen to cover the liabilities) is unique. This suggests than one way to generate different solutions is by introducing a biased-randomised process when sorting the liabilities. To this end, we make use of a skewed probability distribution (the geometric one in our case) to re-order the liabilities list, hence using Monte Carlo simulation to generate a differently ordered lists in each run of the algorithm. The geometric distribution only requires a parameter, $p \in(0,1)$. As $p$ converges to 1 , the list tends to be sorted following the greedy criterion employed by the initial heuristic (i.e., by maturity date). On the contrary, as $p$ converges to 0 , the list tends to follow a uniformly random order. The values in between are the interesting ones, since they represent a compromise between a greedy and a uniform random order. Figure 4 shows the Java code employed to generate the biased-randomisation effect.

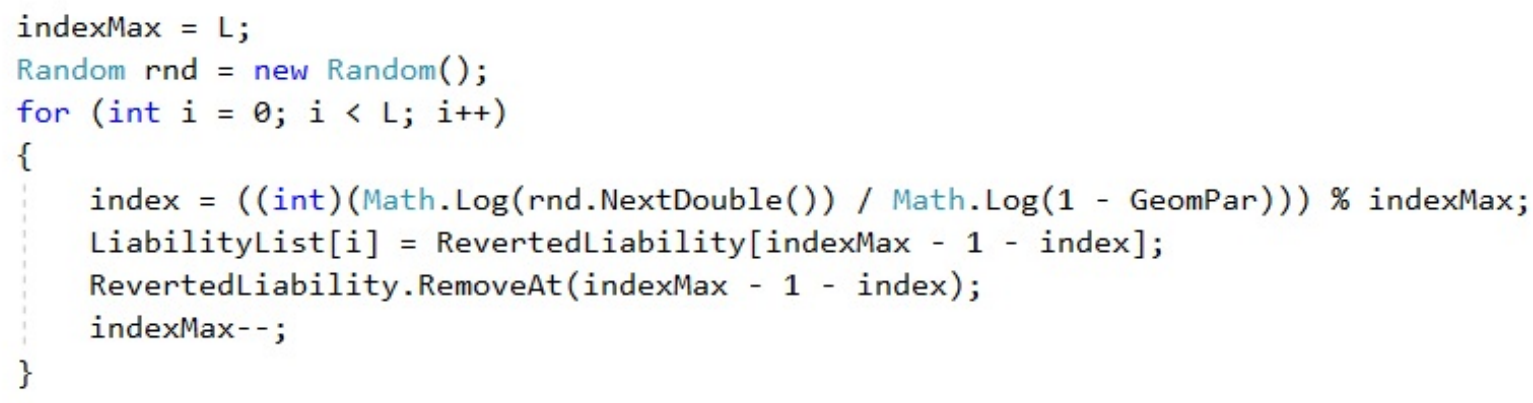

Figure 4: Code for the biased-randomised selection of liabilities.

\section{COMPUTATIONAL EXPERIMENTS}

In order to test our method, we have considered data from a real-life insurance firm. This firm holds 21 assets, which are predominantly government bonds and interest rate swaps. We have considered a discount rate of $1.09 \%$, an interest rate to capitalise resources of $0.5 \%$, and a time span of 33 years. For the geometric distribution, a parameter $p=0.8$ has been selected after a quick trial-and-error process. Also, we have used 100 iterations, a maximum credit of 1 million euros, and assumed that the credit line carries a 5\% interest rate. The origin of the liabilities are pensions, and their present value is 442 million euros.

The assets selected by the actuarial team add up to 490 million euros. Running our algorithm for a few seconds, we found a solution with an associated value of 450 million euros, which represents an $8 \%$ savings with respect the solution provided by the actuarial team. As shown in Figure 5, the solution 
structure is not trivial, so it is not surprising that it could not be found without the help of an algorithm as the one proposed here.

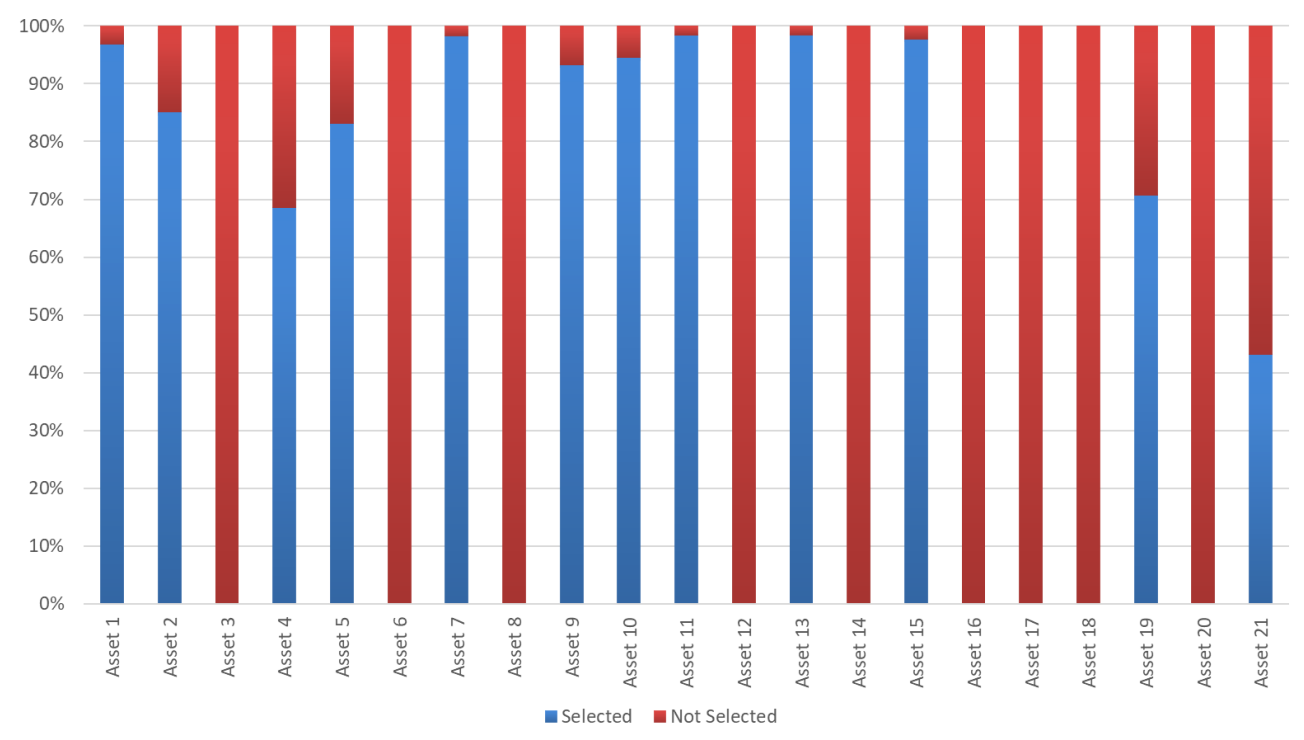

Figure 5: A solution showing the selection of assets and percentages.

Testing different values for the parameter $p$ does not seem to provide significantly better results. The fastest result is found if the original liability order is based on the present value of each liability cash flow. This makes sense, as we first match the largest liability values with the best possible asset. Using this initial order criteria, only 100 iterations are necessary to get a high-quality solution.

\section{CONCLUSIONS}

This paper proposes a solving approach for the asset and liability management problem. Our algorithm makes use of Monte Carlo simulation to transform a greedy heuristic into a probabilistic algorithm. The resulting biased-randomised algorithms is a fast and easy-to-implement method for selecting the minimum amount of assets to cover a portfolio of liabilities. Our method is flexible and it can be easily extended to new constraints, either if they provide from a specific regulation or from the firm's strategy. Our approach can be used in a real-life situation by iteratively applying it to a set of liabilities. According to our computational experiments, the savings it generates can be considerable. Considering that the insurance market is strongly regulated, having an efficient, flexible, and easy-to-implement method to select the proper assets inside a firm's portfolio is extraordinarily important.

As future work, we plan to: (i) extend our probabilistic algorithm into a full metaheuristic one; and (ii) test the algorithm in more benchmark data sets -some of them using real-life data.

\section{ACKNOWLEDGMENTS}

This work has been partially funded by the agreement between the Divina Pastora Seguros and the Universitat Oberta de Catalunya.

\section{REFERENCES}

Adam, A. 2008. Handbook of Asset and Liability Management: From models to optimal return strategies. John Wiley \& Sons. 
Bauer, R., R. Hoevenaars, and T. Steenkamp. 2006. Asset liability management. Oxford: Oxford University Press.

Calvet, L., A. Ferrer, M. I. Gomes, A. A. Juan, and D. Masip. 2016. "Combining statistical learning with metaheuristics for the multi-depot vehicle routing problem with market segmentation". Computers \& Industrial Engineering 94:93-104.

Choudhry, M. 2011. Bank asset and liability management: strategy, trading, analysis. John Wiley \& Sons.

Cornett, M. M., and A. Saunders. 2003. Financial institutions management: A risk management approach. McGraw-Hill/Irwin.

De Armas, J., A. A. Juan, J. M. Marquès, and J. P. Pedroso. 2017. "Solving the deterministic and stochastic uncapacitated facility location problem: from a heuristic to a simheuristic". Journal of the Operational Research Society 68 (10): 1161-1176.

Dempster, M. A., M. Germano, E. A. Medova, and M. Villaverde. 2003. "Global asset liability management". British Actuarial Journal 9 (1): 137-195.

Doering, J., R. Kizys, A. A. Juan, A. Fito, and O. Polat. 2019. "Metaheuristics for rich portfolio optimisation and risk management: Current state and future trends". Operations Research Perspectives 6:100121.

Dominguez, O., D. Guimarans, A. A. Juan, and I. de la Nuez. 2016. "A Biased-randomised large neighbourhood search for the two-dimensional vehicle routing problem with backhauls". European Journal of Operational Research 255 (2): 442-462.

Dutta, G., H. V. Rao, S. Basu, and M. K. Tiwari. 2019. "Asset liability management model with decision support system for life insurance companies: Computational results". Computers \& Industrial Engineering 128:985-998.

Faulin, J., M. Gilibert, A. A. Juan, X. Vilajosana, and R. Ruiz. 2008. "SR-1: A simulation-based algorithm for the capacitated vehicle routing problem". In Proceedings of the 2008 Winter Simulation Conference, 2708-2716. IEEE.

Faulin, J., and A. A. Juan. 2008. "The ALGACEA-1 method for the capacitated vehicle routing problem". International Transactions in Operational Research 15 (5): 599-621.

Fernández, J. L., A. M. Ferreiro-Ferreiro, J. A. García-Rodríguez, and C. Vázquez. 2018. "GPU parallel implementation for asset-liability management in insurance companies". Journal of Computational Science 24:232-254.

Ferstl, R., and A. Weissensteiner. 2011. "Asset-liability management under time-varying investment opportunities". Journal of Banking \& Finance 35 (1): 182-192.

Gondzio, J., and R. Kouwenberg. 2001. "High-performance computing for asset-liability management". Operations Research 49 (6): 879-891.

Gonzalez-Neira, E. M., D. Ferone, S. Hatami, and A. A. Juan. 2017. "A biased-randomized simheuristic for the distributed assembly permutation flowshop problem with stochastic processing times". Simulation Modelling Practice and Theory 79:23-36.

Grasas, A., A. A. Juan, J. Faulin, J. de Armas, and H. Ramalhinho. 2017. "Biased randomization of heuristics using skewed probability distributions: A survey and some applications". Computers \& Industrial Engineering 110:216-228.

Gruler, A., C. Fikar, A. A. Juan, P. Hirsch, and C. Contreras-Bolton. 2017. "Supporting multi-depot and stochastic waste collection management in clustered urban areas via simulation-optimization". Journal of Simulation 11 (1): 11-19.

Gülpinar, N., and D. Pachamanova. 2013. "A robust optimization approach to asset-liability management under time-varying investment opportunities". Journal of Banking \& Finance 37 (6): 2031-2041.

Iyengar, G., and A. K. C. Ma. 2009. "Cash flow matching: a risk management approach". North American Actuarial Journal 13 (3): 370-378.

Juan, A. A., J. Faulin, R. Ruiz, B. Barrios, M. Gilibert, and X. Vilajosana. 2009. "Using oriented random search to provide a set of alternative solutions to the capacitated vehicle routing problem". In Operations 
Research and Cyber-Infrastructure, edited by J. W. Chinneck, B. Kristjansson, and M. J. Saltzman, 331-345. Boston, MA: Springer US.

Kizys, R., A. A. Juan, B. Sawik, and L. Calvet. 2019. "A Biased-randomized iterated local search algorithm for rich portfolio optimization". Applied Sciences - Basel 9 (17).

Kouwenberg, R. 2001. "Scenario generation and stochastic programming models for asset liability management”. European Journal of Operational Research 134 (2): 279-292.

Kouwenberg, R., and S. A. Zenios. 2008. "Stochastic programming models for asset liability management". In Handbook of Asset and Liability Management, 253-303. Elsevier.

Li, D., Y. Shen, and Y. Zeng. 2018. "Dynamic derivative-based investment strategy for mean-variance asset-liability management with stochastic volatility". Insurance: Mathematics and Economics 78:7286.

Li, X., X. Wu, and H. Yao. 2019. "Multi-period asset-liability management with cash flows and probability constraints: A mean-field formulation approach". Journal of the Operational Research Society:1-18.

Martin, S., D. Ouelhadj, P. Beullens, E. Ozcan, A. A. Juan, and E. K. Burke. 2016. "A multi-agent based cooperative approach to scheduling and routing". European Journal of Operational Research 254 (1): $169-178$.

Mitra, G., and K. Schwaiger. 2011. Asset and Liability Management Handbook. Springer.

Quintero-Araujo, C. L., J. P. Caballero-Villalobos, A. A. Juan, and J. R. Montoya-Torres. 2017. "A biasedrandomized metaheuristic for the capacitated location routing problem". International Transactions in Operational Research 24 (5): 1079-1098.

Quintero-Araujo, C. L., A. Gruler, A. A. Juan, and J. Faulin. 2019. "Using horizontal cooperation concepts in integrated routing and facility-location decisions". International Transactions in Operational Research 26 (2): 551-576.

Wei, J., and T. Wang. 2017. "Time-consistent mean-variance asset-liability management with random coefficients". Insurance: Mathematics and Economics 77:84-96.

Zenios, S. A., and W. T. Ziemba. 2007. Handbook of Asset and Liability Management: Applications and case studies, Volume 2. Elsevier.

Zhang, M., and P. Chen. 2016. "Mean-variance asset-liability management under constant elasticity of variance process". Insurance: Mathematics and Economics 70:11-18.

Ziemba, W. T., J. M. Mulvey, H. Moffatt et al. 1998. Worldwide Asset and Liability Modeling, Volume 10. Cambridge University Press.

\section{AUTHOR BIOGRAPHIES}

ARMANDO NIETO is the CEO of Divina Pastora Seguros, one of the largest insurance firms in Spain. He holds a BSc and MSc in Physics from the Universidad de Valencia, and is currently completing his PhD in Computational Finance at the Universitat Oberta de Catalunya. His e-mail address is: anietoran@uoc.edu.

ANGEL A. JUAN is a Full Professor of Operations Research in the Computer Science Dept. at the Universitat Oberta de Catalunya (Barcelona, Spain). Dr. Juan holds a PhD in Industrial Engineering and an MSc in Mathematics. He has published about 80 articles in JCR-indexed journals. His website address is http://ajuanp.wordpress.com and his email address is ajuanp@uoc.edu.

RENATAS KIZYS is a Associate Professor in Finance at the University of Southampton. He holds a MA in Economics (Vilnius University, Lithuania) and a PhD in Economics (University of Alicante, Spain). His research interests centre on Financial Economics. His e-mail address is r.kizys@ soton.ac.uk.

CHRISTOPHER BAYLISS is a post-doctoral researcher in the IN3 - Universitat Oberta de Catalunya. He got a PhD in Computational Mathematics at the University of Nottingham. His main research interests include metaheuristics and simulation-optimisation. His email address is cbayliss@uoc.edu. 


\section{\#SW21}

www.theorsociety.com

f $\boldsymbol{y}$ in $\boldsymbol{0} 00$ @theorsociety 